\title{
PROFESSORES INICIANTES NA EDUCAÇÃO PROFISSIONAL E TECNOLÓGICA: O SILÊNCIO NO BANCO DE TESES DA CAPES NOS ANOS DE
}

2011 E 2012

\author{
PROFESORES PRINCIPIANTES EN LA EDUCACIÓN PROFESIONAL Y \\ TECNOLÓGICA: EI SILENCIO EN EL BANCO DE TESIS DE LA CAPES EN LOS \\ AÑOS 2011 Y 2012
}

WIEBUSCH, Eloisa Maria ${ }^{1}$

\section{RESUMO}

O presente estudo buscou analisar o estado do conhecimento sobre professores iniciantes na educação profissional e tecnológica, a partir das pesquisas de cursos de mestrado e doutorado no Brasil. Realizou-se um mapeamento das produções científicas sobre a temática com base na pesquisa bibliográfica, com abordagem qualitativa e análise de conteúdo proposta por Bardin (2009) para a leitura, análise e interpretação dos dados. Foram identificados 14 trabalhos, sendo 12 dissertações e duas teses sobre os professores iniciantes na educação básica. É um campo inexpressivo de investigações, existe um silenciamento, foi o que revelou o estado do conhecimento. Neste estudo não foi encontrada nenhuma dissertação ou tese sobre os professores iniciantes na educação profissional e tecnológica, mesmo com a expansão dos Institutos Federais, com novos câmpus.

Palavras-chave: Educação profissional e tecnológica. Estado do conhecimento.Professores iniciantes.

\section{RESUMEN}

Este estudio buscó analizar el estado de conocimientoacercade los profesores principiantes en la educación profesional y tecnológica, a partir de las investigaciones en cursos de maestría y doctorado en Brazil. Se llevó a cabo un mapeo de las producciónes científicas sobre el tema basado en una investigación bibliográfica con un enfoque cualitativo y análisis de contenido propuesto por Bardin (2009) para lectura, análisis e interpretación de datos. Fueron identificados 14 trabajos, siendo 12 disertaciones y dos tesis acerca de los profesores principiantes en la educación básica. Se trata de uncampo inexpresivo de investigaciones, hay un silenciamiento, fue lo que mostró el estado del conocimiento. En este estudio no se encontró ninguna disertación o tesis sobre los profesores principiantes en la educación profesional y tecnológica, incluso con la expansión de los Institutos Federales con nuevo campus.

Palabras clave:Educación profesional y tecnológica. Estado de conocimiento. Professores principiantes.

\footnotetext{
${ }^{1}$ Doutoranda em Educação. Pontifícia Universidade Católica do Rio Grande do Sul (PUCRS). Professora do Instituto Federal de Educação, Ciência e Tecnologia Sul-rio-grandense (IFSul). Câmpus Venâncio Aires/RS. E-mail: eloisamw@yahoo.com.br.
}

Criar Educação, Criciúma, v. 6, no1, julho/novembro 2016.- PPGE - UNESC 


\section{INTRODUÇÃO}

No Brasil, com a crescente expansão dos Institutos Federais, com a criação de novos câmpus em todas as regiões brasileiras, cada vez é mais notório o ingresso de novos professores na educação profissional e tecnológica. Muitos são professores iniciantes na docência, oriundos do mundo do trabalho ou dos bancos acadêmicos, muitos são profissionais que não tiveram a docência como primeira opção profissional, são originários de diversas profissões.

A pesquisa buscou analisar o estado do conhecimento sobre os professores iniciantes na educação profissional e tecnológica, considerando as pesquisas desenvolvidas em cursos de mestrado e doutorado no Brasil. Surgiu a inquietação, a necessidade que me motivou a desenvolver a investigação com o seguinte questionamento: $O$ que nos revelam as produções científicas sobre os professores iniciantes na educação profissional e tecnológica, disponíveis no Banco de Teses da Capes, no período de 2011 e 2012 ?

$\mathrm{Na}$ busca de responder a questão, trilhei um longo caminho metodológico. O acesso ao banco de dados ocorreu entre os meses de março a maio de 2015. Procurei produções com as seguintes expressões: "professores iniciantes na educação profissional e tecnológica", "professores iniciantes", "professores principiantes" e "início de carreira docente".

Após a leitura dos títulos e resumos, foram identificados 14 trabalhos, sendo 12 dissertações e duas teses, sobre os professores iniciantes na educação básica. É um campo inexpressivo de investigações. Não encontrei nenhuma dissertação ou tese sobre os professores iniciantes na educação profissional e tecnológica, no período analisado, ora disponível no Banco de Teses da Capes. Enfatizo a necessidade de mais reflexão, atenção e pesquisas sobre inserção dos professores iniciantes, principalmente na educação profissional e tecnológica, por ser uma etapa fundamental na aprendizagem da docência.

\section{A EDUCAÇÃO PROFISSIONAL E TECNOLÓGICA NO BRASIL}

No Brasil, a Rede Federal de Educação Profissional e Tecnológica, tem uma história de mais de 106 anos. Foi em 23 de setembro de 1909, que o Governo Federal Nilo 
Peçanha criou, por meio do Decreto no 7.566, as Escolas de Aprendizes e Artífices, que em 1937 são transformados em Liceus Industriais, e no ano 1942, passam a se chamar de Escolas Industriais e Técnicas, e em 1959, de Escolas Técnicas Federais. No ano de 1978, três escolas do Rio de Janeiro, Minas Gerais e Paraná foram transformadas em Centros Federais de Educação Tecnológica, CEFETs. Em 1994, as demais escolas técnicas se transformam em Centros Federais de Educação Tecnológica, CEFETs e no ano de 2008, em Institutos Federais de Educação, Ciência e Tecnologia.

A Lei no 11.892, de 29 de dezembro de 2008, instituiu a Rede Federal de Educação Profissional, Científica e Tecnológica, vinculada ao Ministério da Educação, criando os 38 Institutos Federais de Educação, Ciência e Tecnologia nos 26 estados da Federação e no Distrito Federal, e as seguintes instituições: Universidade Tecnológica Federal do Paraná, UTFPR; Centros Federais de Educação Tecnológica Celso Suckow da Fonseca, CEFET- RJ e Minais Gerais, CEFET - MG; as Escolas Técnicas vinculadas às Universidades Federais e o Colégio Pedro II.

As instituições elencadas possuem natureza jurídica de autarquia, tem autonomia administrativa, patrimonial, financeira, didático-pedagógico e disciplinar, ou seja, possibilidade de autogestão, com exceção das Escolas Técnicas vinculadas às Universidades Federais.

Os Institutos Federais ofertam educação profissional e tecnológica em diferentes níveis e modalidades de ensino, constitui-se um desafio para o docente atuar na educação básica, educação superior e pós-graduação. Além disso, é preciso articular o tripé que envolve ensino, pesquisa e extensãoem todos os níveis e modalidades de ensino. Pacheco (2011, p. 14) explica que:

a organização pedagógica verticalizada, da educação básica à superior, é um dos fundamentos dos Institutos Federais. Ela permite que os docentes atuem em diferentes níveis de ensino e que os discentes compartilhem espaços de aprendizagem, incluindo os laboratórios, possibilitando o delineamento de trajetórias de formação que podem ir do curso técnico ao doutorado.

A diversidade de níveis e modalidades de ensino possibilita ao docente e ao discente circular por diferentes espaços de aprendizagem, e o discente tem a oportunidade de concluir os estudos na mesma instituição, podendo chegar ao 
doutorado.

Uma das finalidades dos Institutos Federais é contribuir no progresso do desenvolvimento local e regional, na busca da construção da cidadania, por meio do diálogo com as instituições para atender as necessidades locais, melhorando a qualidade de vida da comunidade em que está inserida. Para Pacheco (2011, p. 21) os Institutos: "[...] revelam- se como espaços privilegiados de aprendizagem, inovação e transferência de tecnologias capazes de gerar mudança na qualidade de vida de milhares de brasileiros". Tendo como foco a justiça e inclusão social, a equidade e o desenvolvimento sustentável.

Desde o ano de 2003, houve uma grande expansão da educação profissional e tecnológica, EPT em todos os estados brasileiros, com a criação de novos câmpus, no ano de 2014 eram 562 câmpus, em 512 cidades, principalmente nas regiões sul, sudeste e nordeste do Brasil.

A educação profissional e tecnológica envolve uma diversificação de níveis, modalidades, áreas e uma multiplicidade de saberes. Muitos docentes são iniciantes na profissão, adentram nas salas de aula, muitos sem a formação para a docência, pois não realizaram cursos de licenciatura.

A preocupação com a formação pedagógica dos professores da educação profissional e tecnológica é recente. Foi a Lei de Diretrizes e Bases da Educação Nacional, LDB 9.394/96, que, no capítulo III, nos artigos 39 a 42, tratou da educação profissional pela primeira vez.

\section{PROFESSORES INICIANTES NA DOCÊNCIA}

Os primeiros anos na profissão docente é um período de socialização, de adaptação ao meio, é na prática que se aprende a ser professor e que se constrói a identidade profissional, a aprendizagem da docência vai se construindo, se efetivando no desempenho das atividades docentes, o diálogo e partilha de saberes entre os colegas são fundamentais. Para Cavaco (1999, p. 162) a aprendizagem concretizase "com as práticas do trabalho, interagindo com os outros, enfrentando situações problemas, refletindo sobre as dificuldades e os êxitos e reajustando as formas de ver e proceder". É necessário que o professor invista em estudo permanente por meio da autoformação, estamos imersos em infinitas situações de aprendizagens, Criar Educação, Criciúma, v. 6, nº1, julho/novembro 2016.- PPGE - UNESC 
num processo contínuo, uma construção diária e ininterrupta.

Precisamos intensificar o processo de ação-reflexão-ação sobre a prática pedagógica, mediada pela teoria, pela multiplicidade de saberes, tempos e espaços presentes na contemporaneidade. Para Vaillant e Marcelo Garcia (2012, p. 92): "aprendemos a ser docentes quando somos conscientes do que fazemos e do porquê o fazemos; quando damos razões e refletimos sobre as origens e consequências de nossas condutas e das dos demais".

No contexto, atual nós professores necessitamos pensar em novas formas de ensinar e pensar a educação. Nóvoa (1995, p. 36) explica: "o professor encontra-se num processo de redefinição e diversificação das suas funções, sendo chamado a desempenhar um conjunto alargado de papéis, numa dinâmica de (re)invenção da profissão professor". E parece que é nessa condição que as instituições precisam apostar, investir, contribuir para o desenvolvimento profissional docente. Conforme Vaillant e Marcelo Garcia (2012, p. 167): "o desevolvimento professional docente é uma ferramenta imprescindível para a melhoria escolar".

Recentemente, teóricos como Imbernón (2011), Marcelo Garcia (2009) e Nóvoa (2008) investem no conceito de desenvolvimento profissional docente para substituir os termos formação inicial e continuada. A opção pelo uso desse conceito é explicada por Marcelo Garcia (2009, p. 9):

pensamos que a denominação desenvolvimento profissional se adequa melhor à concepção do professor enquanto profissional do ensino. Por outro lado, o conceito "desenvolvimento" tem uma conotação de evolução e continuidade que, em nosso entender, supera a tradicional justaposição entre formação inicial e formação continuada.

O processo de desenvolvimento profissional docente precisa ser construído ao longo da trajetória pessoal e profissional, cada dia é uma nova aprendizagem, vai se constituindo à medida que os docentes vão adquirindo experiências. Em cada aula ministrada, uma nova aprendizagem, aprendemos com os estudantes, por meio da interação, do trabalho coletivo e de todos os sujeitos envolvidos no processo de aprender e ensinar. Na perspectiva de Marcelo Garcia (2009, p. 15), "o desenvolvimento profissional procura promover a mudança dos professores, para que estes possam crescer enquanto profissionais - e também como pessoas". $\mathrm{Na}$ mesma direção, Nóvoa (2009, p. 38) enfatiza: 
ao longo dos últimos anos, temos dito e (repetido) que o professor é a pessoa, e que a pessoa é o professor. Que é impossível separar as dimensões pessoais e profissionais.Que ensinamos aquilo que somos e que, naquilo que somos, se encontra muito daquilo que ensinamos.

O ser humano está em permanente crescimento pessoal e profissional, possibilidade que existe em cada um de nós como ser inconcluso, sem medidas preestabelecidas para o que pode vir a ser, para tornar-se uma pessoa melhor, emancipada, tendo sempre como horizonte a humanização.

A complexidade da prática pedagógica, para todos os professores, mas principalmente para os que estão no início da inserção docente, é fundamental ter programa de acompanhamento e apoio para contribuir no desenvolvimento profissional. Para Marcelo Garcia (1988, p. 71):

os Programas de Iniciação têm a finalidade de facilitar a adaptação e integração do novo professor na cultura escolar. Trata-se de facilitar ao professor principiante o acesso à ecologia da escola, ou seja, as intenções, estrutura, currículo, pedagogia e sistema de avaliação que caracteriza e diferencia a escola na qual decorrerá o seu ensino.

Os programas de apoio aos professores iniciantes são recentes, começaram a aparecer nos anos 80, são crescentes em alguns países. No Brasil, existem algumas experiências desses programas, como mostra o estudo de André (2012) e outros pesquisadores. Os programas no início da carreira contribuem para aprendizagem da docência, reconhecendo que cada professor tem diferentes trajetórias pessoais e profissionais.

O processo de interação com os professores experientes, colegas que realizam uma prática pedagógica diferenciada e significativa contribui muito para o professor principiante, o aprender com os professores experientes, também chamados de "tutores", "mentores", "orientadores", "guias" são de suma importância para realizar um trabalho coletivo, com partilha de saberes. Reforçam essa ideia Vaillant e Marcelo Garcia (2012, p. 144) ao afirmarem que:

a tarefa que designa ao mentor é a de assessorar didática e pessoalmente ao docente principiante, de forma que se constitua como elemento de apoio. [...] Ele assume um papel de grande importância no programa de inserção, pois é a pessoa que ajuda e dá orientações ao docente principiante, tanto no currículo como na regência de classe.

O apoio e a parceria com um professor experiente/mentor contribuem para a

Criar Educação, Criciúma, v. 6, o1, julho/novembro 2016.- PPGE - UNESC 


\section{CRIAR EDUCAÇÃO}

Revista do Programa de Pós-Graduação em Educação - UNESC
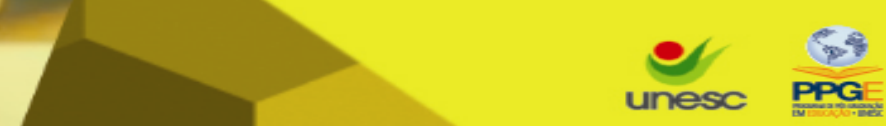

construção da docência e identidade profissional, ambos aprendem, iniciantes e experientes juntos. As interações entre esses colegas ajudam a ultrapassar o isolamento e a solidão da profissão docente, tendo como horizonte o trabalho coletivo e a busca constante da reflexão, análise permanente e crítica da prática pedagógica.

\section{CAMINHOS METODOLÓGICOS}

A constituição do presente estado de conhecimento efetuou-se a partir da consulta a teses e dissertações publicadas, entre os anos de 2011 e 2012, ora disponíveis no Portal da Capes, acerca dos professores iniciantes na educação profissional e tecnológica. Conforme Morosini (2015, p. 102):

\footnotetext{
estado de conhecimento é a identificação, registro, categorização, que levem à reflexão e síntese sobre a produção científica de uma determinada área, em um determinado espaço de tempo, congregando periódicos, teses, dissertações e livros sobre uma temática específica.
}

A construção do estado do conhecimento é de extrema importância para o pesquisador conhecer quais são as produções científicas sobre a temática que se propõe a investigar e assim traçar um cenário sobre o quem vem sendo abordado, bem como para refletir sobre a relevância do tema, na busca de apontar caminhos para novos processos investigativos.

Realizei o mapeamento das produções científicas sobre a temática, a partir da pesquisa bibliográfica, com abordagem qualitativa, sendo considerados alguns dados quantitativos. Os princípios da análise de conteúdo foram utilizados para a leitura, análise e interpretação dos dados, por apresentar possibilidades eficazes para as pesquisas qualitativas, conforme os pressupostos teóricos da francesa Bardin (2009).

\section{DESCOBERTAS DA PESQUISA: RESULTADOS E DISCUSSÕES}

Após a leitura dos títulos e resumos, pode-se dizer que a seleção dos textos priorizou produções com as seguintes expressões: "professores iniciantes na educação profissional e tecnológica", "professores iniciantes", "professores principiantes" e "início de carreira docente". De um total de 40 trabalhos 


\section{CRIAR EDUCAÇÃO}

Revista do Programa de Pós-Graduação em Educação - UNESC

disponibilizados na base de dados pesquisada, foram identificados 14 trabalhos sobre essa temática.

Das 14 pesquisas selecionadas, 12 são dissertações e duas teses. Os trabalhos focam professores iniciantes na educação básica. Esse dado chama a atenção porque não foi encontrado nenhum estudo sobre professores iniciantes na educação profissional e tecnológica e nem sobre professores iniciantes na educação superior, mesmo com a crescente expansão dos Institutos e Universidades Federais, com a implantação de novos câmpus.

No ano de 2011, foram produzidos oito trabalhos e em 2012 foram apresentados seis. As investigações se deram em diferentes áreas do conhecimento, com destaque para a educação física. Quatro pesquisas são sobre os professores iniciantes de educação física, uma em química, uma em matemática e uma em história na Educação de Jovens e Adultos, EJA. Os demais estudos são sobre a prática dos professores recém- graduados, dificuldades e alternativas, socialização e construção da identidade, professoras iniciantes bem sucedidas, aprendizagem dos professores e o desenvolvimento profissional. Um aspecto interessante: nenhuma pesquisa teve como foco os programas de apoio aos professores iniciantes, talvez por serem poucos e recentes no Brasil.

Os Programas de Pós-Graduação em Educação com maior evidência foram da Pontifícia Universidade Católica do Paraná, PUCPR, com três investigações, e da Universidade do Vale do Rio dos Sinos, UNISINOS, com duas. Os demais com uma pesquisa são da Pontifícia Universidade Católica de São Paulo, PUCSP, Universidade Nove de Julho, UNINOVE, Universidade da Região de Joinville, UNIVILLE, Universidade Federal Rural do Rio de Janeiro, UFRRJ, Universidade Federal de Minas Gerais, UFMG, Universidade Federal do Rio Grande do Norte, UFRN, Universidade Federal de Mato Grosso, UFMT, Universidade Estadual de Londrina, UEL e Universidade Estadual Paulista Júlio de Mesquita Filho, UNESP. Portanto, os programas são de mais instituições de ensino privadas do que públicas, com destaque para as das regiões Sul e Sudeste do Brasil.

A metodologia usada na maioria das pesquisas foi a abordagem qualitativa. Em relação aos instrumentos utilizados para a coleta de dados, observou-se 0 predomínio de questionários, entrevistas semiestruturadas e observação 
participante. Para a leitura, análise e interpretação, a mais usada foi a análise de conteúdo (BARDIN, 2009). Os sujeitos de pesquisa foram docentes em início de carreira, com até cinco anos de exercício profissional, que vivenciam o rito de passagem de acadêmicos para docentes. Marcelo Garcia (1999, p. 113) observa que:

os primeiros anos de ensino são especialmente importantes porque os professores devem fazer a transição de estudantes para professores, e, por isso, surgem dúvidas, tensões, sendo necessário adquirir um conhecimento e competência profissional adequados num curto espaço de tempo.

Nessa direção, Gabardo (2012), na sua dissertação, menciona o início da docência como um período de tempo que compreende os primeiros anos na carreira, pois os professores fazem a transição de estudantes a docentes.

Os sujeitos participantes das investigações eram professores que atuavam em diferentes níveis de ensino da educação básica: educação infantil, anos iniciais e finais do ensino fundamental e ensino médio. Somente um estudo foi na modalidade EJA. A maioria exercia suas funções em escolas públicas das redes municipal e estadual de ensino.

Outro aspecto que merece destaque são os autores mais recorrentes na maioria dos trabalhos. Os teóricos mais citados são: Huberman (1992), Imbernón (1994), Marcelo Garcia (1992, 1999), Nóvoa (1995) e Tardif (2002). Esses são os principais pesquisadores da atualidade que se dedicam a estudar a formação de professores, o início da docência, as diferentes fases do processo de desenvolvimento profissional docente.

As pesquisas analisadas apresentaram uma contribuição relevante sobre a importância do período de iniciação profissional de professores iniciantes. Gabardo (2012) menciona que as primeiras experiências vividas pelos docentes em início de carreira têm influência direta sobre a decisão de continuar ou não na profissão, por ser uma etapa marcada por sentimentos contraditórios que desafiam cotidianamente a prática docente. Nessa mesma perspectiva, reforça Freitas (2011) que os primeiros anos da carreira retratam ser um momento especial, são os mais difíceis da vida profissional, de muitas aprendizagens, de sobrevivência, numa realidade desconhecida e da mudança de conhecimentos, valores e crenças sobre a profissão que tinham adquirido. 
A inserção na profissão docente é acompanhada de diversos sentimentos e o choque de realidade, apontam Huberman (1992) e Veenman (1984) ao se referirem às circunstâncias que passam muitos docentes no início da carreira. A pesquisa de mestrado desenvolvida por Campos (2012) revelou que o ingresso na profissão é marcado por sentimentos ambíguos de euforia e medo, passamos por um choque de realidade.

Muitos são os desafios enfrentados pelos professores ao ingressar na docência. Como mostra Pilz (2011), o início da carreira é marcado por dificuldades referentes à indisciplina, motivação, planejamento de aulas, aprendizagem dos alunos e também à falta de apoio da escola. Marcelo Garcia (1999, p. 113) classifica a etapa de inserção docente como "um período de tensões e aprendizagens intensivas em contextos geralmente desconhecidos, e durante o qual os professores principiantes devem adquirir conhecimento profissional, além de manter certo equilíbrio pessoal".

\section{CONSIDERAÇÕES PARA CONTINUAR PESQUISANDO}

O propósito desta investigação foi realizar uma análise da produção científica indexada na Capes, no período de 2011 e 2012, sobre os professores iniciantes na educação profissional e tecnológica. Constatou-se que é um campo inexpressivo de investigações foi o que revelou o estado do conhecimento. Existe um silenciamento sobre a temática. Não encontrei nenhuma dissertação ou tese sobre os professores iniciantes na educação profissional e tecnológica e poucas produções acadêmicas sobre os professores iniciantes na educação básica.

Em alguns países, o apoio aos professores iniciantes vem sendo assinalado pelas demandas por uma educação de qualidade. No Brasil, o início da docência é uma temática pouco explorada por parte das instituições formadoras de professores, instituições de ensino, políticas públicas e pesquisadores.

A constatação das poucas pesquisas nos remete a Lima (2006), Marcelo Garcia (1999), e Mariano (2005) que sinalizam que existem escassez e carência significativa de pesquisas sobre a temática. Estudos recentes de Gatti (2012) e Romanowski (2012) confirmam que ainda são insuficientes as pesquisas sobre os professores iniciantes. Portanto, há muito a se pesquisar, investigar, sobre os professores iniciantes na educação profissional e tecnológica, tendo em vista que Criar Educação, Criciúma, v. 6, nº1, julho/novembro 2016.- PPGE - UNESC 


\section{CRIAR EDUCAÇÃO}

Revista do Programa de Pós-Graduação em Educação - UNESC

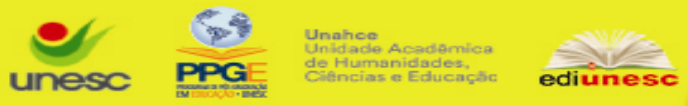

muitos desses professores realizaram a graduação em bacharel ou tecnólogo, não cursaram uma licenciatura e não têm formação pedagógica para a docência.

Os professores iniciantes na docência merecem e necessitam serem acolhidos e ajudados no início da carreira, pelas escolas, pelos colegas e professores experientes. Os programas de apoio são fundamentais nessa etapa de negação ou afirmação do ser docente. As mudanças exigem novos olhares para a inserção profissional dos professores iniciantes. 


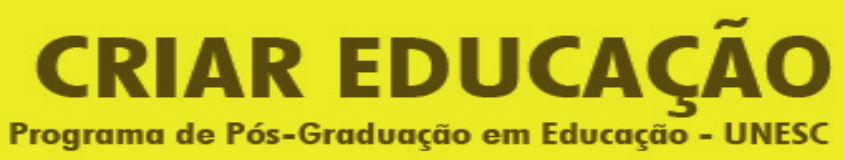

Revista do Programa de Pós-Graduação em Educação - UNESC

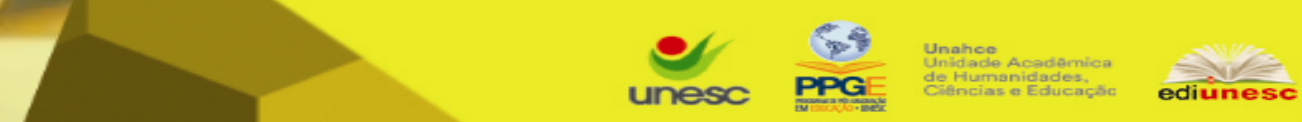

\section{REFERÊNCIAS}

ANDRÉ, Marli. Políticas e programas de apoio aos professores iniciantes no Brasil. In: CONGRESSO INTERNACIONAL SOBRE PROFESSORADO PRINCIPIANTE E INSERCIÓN PROFESIONAL A LA DOCENCIA, 3. 2012, Santiago do Chile. Anais... Santiago do Chile, 2012.

BARDIN, Laurence. Análise de conteúdo. Lisboa: Edições 70, 2009.

BRASIL.Lei no 9.394, de 20 de dezembro de 1996. Estabelece as Diretrizes e Bases da Educação Nacional. Diário Oficial da União. Brasília, 30 dez. 1996.

Lei no 11.892, de 29 de dezembro de 2008. Institui a Rede Federal de Educação Profissional, Científica e Tecnológica. Diário Oficial da União. Brasília, 30 dez. 2008. Seção 1, p. 1.

CAMPOS, Rebeca Ramos. Necessidades de formação de professoras principiantes da educação infantil/pré-escola, 2012. vi, 145 f. Dissertação (Mestrado Acadêmico em Educação). Universidade Federal do Rio Grande do Norte, 2012. Disponível em: <http://bancodeteses.capes.gov.br/>. Acesso em: 30 mar.

2015.

CAVACO, Maria Helena. Ofício do professor: o tempo e as mudanças. In: NÓVOA, Antonio. Profissão Professor. Porto: Porto Editora, 1999. p. 155-191.

FREITAS, Rosinei de Cristina de.Estudo multicasos sobre a socialização profissional de professores de educação física em início de carreira, 2011. vi. 99 f. Dissertação (Mestrado Acadêmico em Educação). Universidade Federal Rural do Rio de Janeiro, 2011. Disponível em:<http://bancodeteses.capes.gov.

br/>. Acesso em: 23 mar. 2015.

GABARDO, Claudia Valeria Lopes. 0 início da docência no ensino fundamental da rede municipal de ensino, 2012. vi. 126 f. Dissertação (Mestrado Acadêmico em Educação). Universidade da Região de Joinville, 2012. Disponível em: <http://bancodeteses.capes.gov.br/>. Acesso em: 23 mar. 2015.

GATTI, Bernadete Angelina. O início da carreira docente no Brasil: formas de entrada, primeiras experiências profissionais e políticas educacionais. In:

CONGRESSO INTERNACIONAL SOBRE PROFESSORADO PRINCIPIANTE E INSERCIÓN PROFESIONAL A LA DOCENCIA, 3. 2012, Santiago do Chile. Anais... Santiago do Chile, 2012.

HUBERMAN, Michael. O ciclo de vida profissional dos professores. In: NÓVOA, Antonio. (org.).Vidas de professores. Lisboa: Porto, 1992. p. 31-61.

IMBERNÓN, Francisco. La formación del professorado. Buenos Aires: Paidós, 1994.

Criar Educação, Criciúma, v. 6, nº1, julho/novembro 2016.- PPGE - UNESC 


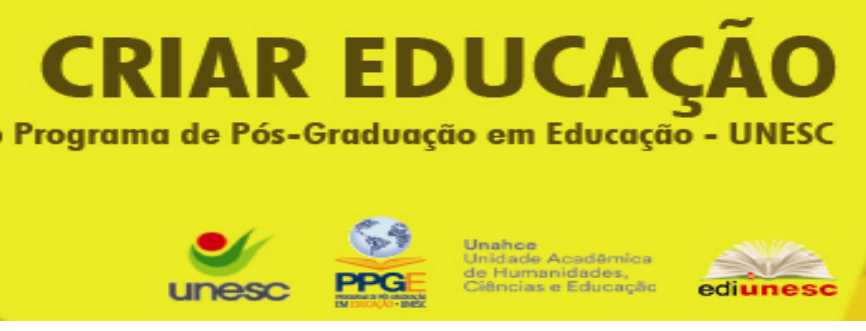

. Formação docente e profissional: formar-se para a mudança e incerteza.

9. ed. São Paulo: Cortez, 2011.

LIMA, Emília Freitas de.(Org.).Sobrevivências no início da docência. Brasília: Líber Livro Editora, 2006.

MARCELO GARCIA, Carlos. Avances en el estudio del pensamiento del

profesor. Sevilha: Servicio de Publicaciones de la Universidad, 1988.

A formação de professores: novas perspectivas baseadas na investigação sobre o pensamento do professor. In: NÓVOA, Antônio. Os professores e a sua formação. Lisboa: Dom Quixote, 1992. p. 51-76.

Formação de professores: para uma mudança educativa. Porto: Porto Editora, 1999.

Desenvolvimento profissional docente: passado e futuro. Sisifo: Revista de Ciências da Educação.Lisboa, n. 8, p. 7-22, jan/abr. 2009.

MARIANO, André Luiz Sena. Aprendendo a ser professor no início da carreira: um olhar a partir da ANPEd. 2005. Disponível em: <http://www.anped.org.br>. Acesso em: 10 abr. 2016.

MOROSINI, Marília Costa. Estado do conhecimento e questões do campo científico.Revista Educação, Santa Maria, v. 40, n. 11, p. 101-116, jan./abr. 2015.

NÓVOA, Antônio.Profissão professor. Porto: Porto Editora, 1995.

O regresso dos professores. Livro da Conferência Desenvolvimento Profissional de Professores para a Qualidade e para a Equidade da Aprendizagem ao Longo da Vida. Lisboa: Ministério da Educação, 2008.

Professores: imagens do futuro presente. Lisboa: Educa, 2009.

PACHECO, Eliezer (Org.). Institutos Federais: uma revolução na educação profissional e tecnológica. São Paulo: Moderna, 2011.

PILZ, Cristiane Aparecida da Silva.Iniciação profissional de professores de matemática: dificuldades e alternativas, 2011. vi. 152 f. Dissertação (Mestrado Acadêmico em Educação). Pontifícia Universidade Católica do Paraná, 2011. Disponível em: <http://bancodeteses.capes.gov.br/>. Acesso em: 23 mar. 2015.

ROMANOWSKI, Joana Paulin. Professores Principiantes no Brasil: questões atuais. In: CONGRESSO INTERNACIONAL SOBRE PROFESSORADO PRINCIPIANTE E INSERCIÓN PROFESIONAL A LA DOCENCIA, 3., 2012, Santiago do Chile. Anais... Santiago do Chile, 2012.

TARDIF, Maurice. Saberes docentes e formação de professores. Petrópolis: Vozes, 2002.

Criar Educação, Criciúma, v. 6, ํo1, julho/novembro 2016.- PPGE - UNESC 
VAILLANT, Denise; MARCELO GARCIA, Carlos.Ensinando a ensinar: as quatro etapas de uma aprendizagem. Curitiba: UTFPR, 2012.

VEENMAN, S. Perceived Problems of beginning teachers. In: Review of Educactional Research Summer. v. 54, n. 2, 1984, p. 143-178. 